\title{
Terapia antirretroviral em gestantes portadoras do HIV
}

\section{Antiretroviral therapy in HIV-positive pregnant women}

DOI: 10.46814/lajdv3n4-071

Recebimento dos originais: 01/05/2021

Aceitação para publicação: 31/06/2021

\author{
Sebastião Junior Henrique Duarte \\ Doutor em Ciências da Saúde \\ Universidade Federal de Mato Grosso do Sul \\ Unidade 9 - Cidade Universitária, Campo Grande-MS, 79070-900 \\ E-mail: sjhd.ufms@gmail.com
}

\section{RESUMO}

Este estudo de revisão integrativa da literatura teve como objetivo revisar as evidências descritas em protocolos assistenciais às gestantes com HIV quanto ao tratamento com antirretroviral. Teve-se por questão norteadora: como são usadas as terapias antirretrovirais em gestantes? Os dados foram obtidos por meio de busca nas bases de dados LILACS e SCIELO, abrangendo o período de 2010 até 2016, nos idiomas português, inglês e espanhol. Identificou-se 17 artigos, dos quais seis atenderam aos critérios de inclusão adotados. Os resultados foram organizados em quadro. A caracterização revelou que a maioria dos autores são formados em medicina, realizaram estudo retrospectivo em bases de dados e 66,6\% das publicações ocorreram no Brasil. Os resultados revelaram que o correto uso da terapia antirretrovital descrita em protocolo atualizado reduz o potencial de transmissão vertical e possibilita o nascimento de recém-nascidos sem o vírus da imunodeficiência adquirida.

Descritores: Protocolos Clínicos. Fármacos Anti-HIV. Gestantes.

\begin{abstract}
This integrative literature review study aimed to review the evidence described in care protocols for pregnant women with HIV regarding antiretroviral treatment. The guiding question was: How are antiretroviral therapies used in pregnant women? The data were obtained by searching the LILACS and SCIELO databases, covering the period from 2010 to 2016, in Portuguese, English and Spanish. Seventeen articles were identified, six of which met the inclusion criteria adopted. The results were organized in a table. The characterization revealed that most authors are medical graduates, conducted retrospective study in databases and $66.6 \%$ of publications occurred in Brazil. The results revealed that the correct use of antiretroviral therapy described in an updated protocol reduces the potential for vertical transmission and enables the birth of newborns without acquired immunodeficiency virus.
\end{abstract}

Key words: Clinical Protocols. Anti-HIV drugs. Pregnant Women.

\section{INTRODUÇÃO}

A Síndrome da Imunodeficiência Adquirida (AIDS) é um dos principais problemas de saúde pública, em especial nas mulheres grávidas, em virtude do potencial de transmissão ao feto quando não 
se tem o diagnóstico em tempo hábil para manejar adequadamente o pré-natal, através da realização de exames e uso de medicamentos que reduzam a quantidade de vírus no organismo materno. ${ }^{1}$

O uso da terapia antirretroviral (TARV) ${ }^{2}$ pode ser considerada uma inovação na assistência prénatal, tendo em vista o potencial de redução da transmissão vertical do vírus da imunodeficiência humana (HIV), seja por via placentária até o contato com o sangue materno na ocasião do nascimento. Com isso, mulheres portadoras do vírus HIV têm a possibilidade de gestar e conceber bebês sadios.

Dados do Ministério da Saúde ${ }^{3}$ registram o aumento da taxa de detecção do HIV em gestantes nos últimos anos, onde em 2015 houve 7.901 casos registrados, o que representa a taxa de 2,7 gestantes infectadas a cada 1.000 nascidos vivos. Ressalta-se que o acesso à assistência pré-natal e a atenção qualificada proporciona desde o diagnóstico, manejo e tratamento das patologias em mulheres grávidas e respectivos parceiros, também a melhoria na confiabilidade dos dados estatísticos.

No Brasil, a TARV 4 consta na lista de medicamentos disponibilizados pelo Sistema Único de Saúde (SUS), portanto é de acesso gratuito. O uso da TARV suprime a carga viral e aumenta a expectativa de vida. Contudo, deve ter acompanhamento por profissionais de saúde, haja vista os efeitos indesejados que podem ensejar, inclusive, o abandono da terapia.

Infelizmente o tratamento do HIV ainda não ocorre universalmente no mundo. Nesse sentido, a agenda da Organização das Nações Unidas para o período 2016 a 2030, em seus 17 objetivos de desenvolvimento sustentáveis ${ }^{5}$, traçou como objetivo 3: assegurar uma vida saudável e promover o bem-estar para todos, em todas as idades, cuja meta 3.3 tem o compromisso de até 2030 acabar com as epidemias de AIDS, tuberculose, malária e doenças tropicais negligenciadas, e combater a hepatite, doenças transmitidas pela água, e outras doenças transmissíveis.

Tomando como foco ações de combate ao HIV/AIDS em recém-nascidos ${ }^{6}$, é primordial o desenvolvimento de estratégias que incluem: o início precoce do pré-natal; a realização de todos os exames de rotina pré-natal e os específicos a depender da situação, como é a necessidade da contagem de células T para gestantes portadoras do HIV; a oferta do TARV e todo acompanhamento profissional.

Parte-se do pressuposto de que se a equipe prenatalista atuar em consonância com os protocolos assistenciais atualizados, então a assistência será qualificada na gestação, parto e nascimento e o desfecho favorável para o binômio mãe-bebê, incluindo a realização do parto por via vaginal.

$\mathrm{Na}$ intenção de contribuir com as evidências científicas voltadas à atenção às gestantes portadoras do HIV é que esse estudo tem por objetivo revisar as evidências descritas em protocolos assistenciais às gestantes com HIV quanto ao tratamento com antirretroviral. 


\section{MÉTODO}

Essa revisão integrativa da literatura consiste no trabalho de conclusão de curso de especialização em enfermagem ginecológica e obstétrica e foi desenvolvida em seis etapas, primeiro caracterizou-se o tema em forma de questão norteadora: como são usadas as terapias antirretrovirais em gestantes? Na segunda fase utilizou-se como critérios de inclusão os textos completos nos idiomas português, inglês e espanhol, publicados entre os anos 2010 a 2016 em periódicos nacionais e internacionais. Excluíram-se teses, dissertações, artigos não disponíveis na íntegra, livros e os que não respondiam a questão norteadora. Artigos publicados em mais de uma base de dados foram considerados somente uma vez.

Foi realizado busca bibliográfica nas bases de dados Literatura Latino-Americana e do Caribe em Ciências da Saúde (LILACS) Scientific Electronic Library Online (SciELO).

Os descritores utilizados foram controlados associados aos operadores booleanos: "terapia antirretroviral" AND "pré-natal”, "terapia antirretroviral” AND "gestação" e "terapia antirretroviral” AND gravidez". Os termos de pesquisa no PubMed foram baseados no MeSH (Medical Subject Headings) e nas demais bases utilizou-se os termos constantes no DeCS (Descritores em Ciências da Saúde).

Na terceira fase foi realizada síntese dos artigos selecionados pelos pesquisadores, etapa em que se elaborou o instrumento de categorização dos artigos com vistas à sistematização das informações. Foram consideradas as variáveis: autores, objetivo do estudo e principais resultados, o que permitiu a avaliação de dados referentes à originalidade, intervenções, recomendações e os resultados, assim como os níveis de evidência: (I) revisões sistemáticas ou metaanálises de relevantes ensaios clínicos; (II) ensaio clínico randomizado; (III) ensaio clínico sem randomização; (IV) estudos de coorte e de caso-controle; (V) revisão sistemática de estudos descritivos e qualitativos; (VI) um único estudo descritivo ou qualitativo; (VII) opinião de um comitê de especialistas. ${ }^{7}$

A análise da síntese dos dados contemplou a quarta fase do estudo que teve como meta a elaboração de banco de dados elaborado pelos autores e identificar a semelhança no tipo de pesquisa aplicada e ambiente de estudo. Após a seleção, os estudos foram codificados com uma sequência alfanumérica (E1, E2, E3 e assim sucessivamente), a fim de facilitar a identificação. Todos foram referenciados.

$\mathrm{Na}$ quinta fase da pesquisa, realizou-se a discussão dos resultados, destacando as recomendações para o uso da terapia antirretroviral em gestantes, bem como as principais conclusões de cada estudo.

Os resultados foram dispostos em quadro e confrontados à luz da produção científica veiculada em periódicos, constituindo-se a sexta fase metodológica deste estudo. 


\section{RESULTADOS}

$\mathrm{Na}$ presente revisão integrativa foram analisados seis artigos que atenderam aos critérios de inclusão, conforme apresentado no Quadro 1. As fontes de publicação foram variadas totalizando quatro periódicos nacionais e os da área de infectologia $(9,10,11$ e 13) que colaboraram com 66,6\% da amostra.

As publicações concentraram-se no período de 2010 a 2012, embora algumas revistas possam estar com atraso na publicação de números do ano de 2016, com isso a possibilidade de artigos não disponíveis no momento da coleta de dados. Verifica-se que a maioria $(66,6 \%)$ das produções científicas tem origem no Brasil $(8,9,11$ e 12), outros 16,7\% refere-se a estudo realizado no Chile e $16,7 \%$ no Uruguai, totalizando $33,4 \%$ estudos em outros países. Dos estudos brasileiros, a maioria $(50 \%)$ foi realizado na região nordeste.

Quanto à formação acadêmica do primeiro autor, nota-se que a maioria (80\%) foram publicados por médicos $(8,9,10$ e 13), seguidos de $20 \%$ de publicações por enfermeiros (11 e 12).

$\mathrm{Na}$ análise da metodologia empregada, identificou-se que $66,7 \%$ dos estudos foram por meio da análise documental $(8,9,10$ e 11) e 33,3\% desenvolveram estudos com dados primários (12 e 13). Assim, a amostra obteve os níveis de evidência VI (8, 9, 10 e 11), nível de evidência IV (13) e nível de evidência III (12).

Informações referente aos objetivos e principais resultados dos estudos são apresentadas no quadro 1.

Quadro 1 - Caracterização das amostras, segundo variáveis: autores, objetivo e resultados

\begin{tabular}{|c|l|l|}
\hline Código & \multicolumn{1}{|c|}{ Objetivos do estudo } & \multicolumn{1}{c|}{ Resultados } \\
\hline $\mathrm{E}^{8}$ & $\begin{array}{l}\text { Avaliar a prevalência do } \\
\text { HIV em gestantes, a taxa de } \\
\text { transmissão vertical (TV) e } \\
\text { a perda de seguimento dos } \\
\text { recém-nascidos (RNs). }\end{array}$ & $\begin{array}{l}\text { No período, foram realizados 53.936 partos, 305 gestantes } \\
\text { tiveram o diagnóstico de HIV, com prevalência de 0,56\%. } \\
\text { Dessas, 283 tiveram RN vivos. A perda do seguimento dos } \\
\text { meses, encontrou-se taxa de TV de 5.47\%. }\end{array}$ \\
\hline $\mathrm{E}^{9}$ & $\begin{array}{l}\text { Estudar a evolução clínica e } \\
\text { laboratorial de crianças } \\
\text { vivendo com HIV/AIDS } \\
\text { decorrente da transmissão } \\
\text { vertical. }\end{array}$ & $\begin{array}{l}\text { Foram avaliadas 80 crianças. Observou-se que em 56 (70\%) } \\
\text { crianças, o diagnóstico da infecção pelo HIV na mãe deu-se } \\
\text { após o parto e que em 44 (55\%) o parto foi via vaginal. } \\
\text { Amamentação ao seio materno foi documentada em 56 (70\%) } \\
\text { crianças e esta variou de um mês até mais de 12 meses. A não } \\
\text { utilização ou uso incompleto do Protocolo ACTG 076 foi } \\
\text { documentado em 63 (78,5\%) casos. }\end{array}$ \\
\hline $\mathrm{E}^{10}$ & $\begin{array}{l}\text { Descrever a experiência da } \\
\text { transmissão vertical durante } \\
\text { anos e as medidas } \\
\text { adotadas, através de dados } \\
\text { controlados pelo Centro } \\
\text { Nacional de Referência } \\
\text { Obstétrico- Pediátrico do } \\
\text { Uruguai. }\end{array}$ & $\begin{array}{l}\text { 204 (15,1\%) crianças foram infectadas. A porcentagem de } \\
\text { transmissão vertical (TV) diminui ao longo dos anos; entre } \\
\text { 2003 e 2009 decresceu 6\%. Fatores protetivos contra } \\
\text { transmissão vertical do HIV foram a terapia antirretroviral } \\
\text { (TARV) durante a gravidez, cesariana eletiva e não } \\
\text { amamentação. Mulheres que não receberam a TARV tiveram } \\
\text { uma porcentagem de TV de 50,3\%. }\end{array}$ \\
$\begin{array}{l}\text { Avaliar a aplicação do } \\
\text { protocolo Aids Clinical }\end{array}$ & $\begin{array}{l}\text { Entre as 110 mulheres grávidas e os recém-nascidos expostos, } \\
\text { o protocolo ACTG 076 foi totalmente utilizado em apenas }\end{array}$ \\
\hline
\end{tabular}




\begin{tabular}{|c|c|c|}
\hline & $\begin{array}{l}\text { Trial Group } 076 \text { na } \\
\text { maternidade de referência, } \\
\text { no estado de Sergipe, } \\
\text { nordeste do Brasil. }\end{array}$ & $\begin{array}{l}31,8 \% \text { dos participantes. Durante o período pré-natal, a } \\
\text { zidovudina (ZDV) foi tomada por } 79,1 \% \text { das mulheres } \\
\text { grávidas. Apenas } 49,1 \% \text { dos pacientes soropositivos para } \\
\text { HIV usaram ZDV durante o parto. Duas }(1,8 \%) \text { crianças } \\
\text { foram consideradas infectadas e } 50(45,5 \%) \text { não tiveram } \\
\text { diagnóstico conclusivo até o fim da pesquisa. }\end{array}$ \\
\hline$E^{12}$ & $\begin{array}{l}\text { Avaliar a testagem anti- } \\
\text { HIV durante a assistência } \\
\text { pré-natal e ao parto no } \\
\text { Sistema Único de } \\
\text { Saúde. }\end{array}$ & $\begin{array}{l}\text { Segundo informação das } 835 \text { parturientes, } 86,7 \% \text { dispunham } \\
\text { de sorologia não reagente do pré-natal e } 55,7 \% \text { foram } \\
\text { submetidas ao teste rápido anti-HIV no hospital; em } 49,9 \% \\
\text { dos casos o procedimento relativo ao teste rápido anti-HIV no } \\
\text { hospital foi considerado adequado: mães com status ignorado } \\
\text { de HIV no pré-natal submetidas ao teste rápido e mães com } \\
\text { status conhecido não submetidas ao mesmo. }\end{array}$ \\
\hline $\mathrm{E}^{13}$ & $\begin{array}{lrr}\begin{array}{l}\text { Descrever } \\
\text { imunológico }\end{array} \text { clínico em } \\
\text { mulheres grávidas que } \\
\text { adquiriram } \\
\text { transmissão } & \text { vertical, } \\
\text { tratamentos } & \text { recebidos, } \\
\text { monitoramento da gravidez } \\
\text { e características do recém- } \\
\text { nascido no Chile. }\end{array}$ & $\begin{array}{l}\text { Das } 358 \text { pacientes HIV positivas infectadas verticalmente, } \\
\text { cinco mulheres ficaram grávidas, entre } 14 \text { e } 24 \text { anos. As } \\
\text { gravidezes foram monitorizadas. Elas receberam duas a cinco } \\
\text { terapias antiretrovirais. O protocolo completo foi realizado } \\
\text { em todos os binômios. As cargas virais pré-natais } \\
\text { indetectáveis variaram de } 4.700 \text { cópias ARN/ml. Cinco filhos } \\
\text { vivos nasceram por cesariana, quatro deles com } 37 \text { semanas } \\
\text { de gestação completa e uma delas com } 34 \text { semanas de } \\
\text { gestação. Todos receberam zidovudina (AZT) por } 6 \text { semanas. } \\
\text { A taxa CD4 às } 72 \text { horas de vida variou de } 48 \% \text { a } 74,6 \% \text {. } \\
\text { Todas as crianças nasceram não infectadas com HIV. Apenas } \\
\text { dois apresentaram anemia leve. }\end{array}$ \\
\hline
\end{tabular}

\section{DISCUSSÃO}

A caracterização dos estudos revelou escassez de estudos publicados em revistas indexadas pelas fontes pesquisadas, embora haja várias revistas da área de infectologia, situação que chama atenção para o incremento de publicações de assunto relevante, ainda mais por profissionais da equipe multiprofissional, no sentido de trazerem contribuições para a reorganização dos serviços de saúde materno e infantil.

A escolha de estudos publicados a partir do ano de 2010 decorre de mudanças nas políticas de saúde pública nesse período, embora o diagnóstico e tratamento do HIV em gestantes seja anterior a esse período, porém, os protocolos assistenciais foram sendo aperfeiçoados e servem de referencial para as condutas baseadas em evidências científicas.

A análise dos estudos constitui em desafios que já deveriam ter sido superados, especialmente no Brasil, que conta com sistema universal, integral e equitativo de saúde, efetivado pelo Sistema Único de Saúde (SUS), que prevê um conjunto de ações assistenciais à toda população. Especificamente às mulheres, o SUS assegura desde a contracepção, pré-natal, parto ao puerpério, na perspectiva do cuidado integral ${ }^{14}$.

Em relação ao manejo da gestante portadora do vírus HIV, os dados mostraram a divergência em localidades aonde não se cumpre todo o protocolo contendo as recomendações do uso de antirretrovirais, tanto em mulheres grávidas quando em recém-nascidos, acarretando na transmissão 
vertical e a perpetuação da morbidade e mortalidade decorrente da síndrome da imunodeficiência adquirida $^{15}$.

Dos estudos realizados no Brasil ${ }^{(8,9,11,12)}$, são inquietantes as situações descritas, considerando que nem toda gestante teve o acesso ao exame de sorologia para detecção do vírus HIV, mesmo sendo um dos exames de rotina pré-natal. Além disso, a perda do segmento de recém-nascido de mãe infectada coloca em dúvidas se o trabalho em saúde está mesmo sendo em equipe, tomando por referência o modelo de processo de trabalho da Estratégia Saúde da Família ${ }^{16}$.

A detecção e tratamento do HIV não deve se dar na fase pré-parto ou puerpério, afinal os medicamentos antirretrovirais são oferecidos pelo SUS, porém, é preciso ter o diagnóstico em tempo de se proceder a administração medicamentosa nas gestantes e, posteriormente, nos recém-nascidos. Conforme é recomendado tanto pela literatura como por protocolos do Ministério da Saúde ${ }^{14}$.

Os estudos internacionais ${ }^{(10,13)}$ contribuíram com a ideia de que o emprego adequado das fases descritas em protocolo, favoreceram o nascimento de bebês saudáveis e, provavelmente, as gestantes também receberam assistência, além dos medicamentos. Esse modelo pode ser desenvolvido no Brasil.

A pesquisa sorológica durante o pré-natal é fundamental para prevenção da transmissão vertical, juntamente com a adesão e uso adequado da TARV pela gestante infectada. É um processo longo e árduo, que deve ser construído com confiança e acolhimento ${ }^{17}$ por parte da equipe de saúde, pois a gestante sente-se fragilizada física e emocionalmente com o resultado sorológico. O suporte psicológico no momento da confirmação diagnóstica é de extrema importância para adesão da mesma ao tratamento ${ }^{18}$.

O seguimento correto do pré-natal e o tratamento prévio ao parto, além de diminuir a incidência de transmissão vertical do vírus ${ }^{19}$, possibilita outros métodos, inclusive o parto vaginal, pode evitar procedimentos desnecessários como a testagem rápida no intraparto de pacientes já diagnosticadas e tratadas,

\section{CONSIDERAÇÕES FINAIS}

As limitações do estudo residem nas fontes pesquisadas, constituindo em motivação para outras pesquisas que abranjam maior número de bases de indexação de estudos científicos.

Todos os estudos recomendam o protocolo ACTG 076 como melhor evidência no manejo de gestantes com HIV, quanto ao tratamento com medicamentos antirretrovirais. Assim, os profissionais de saúde contam com esse recurso bibliográfico, capaz de guiar as condutas que possam promover o cuidado seguro e a redução da transmissão vertical. 


\section{REFERÊNCIAS}

1. Siemieniuk RAC, Lytvyn L, Mah Ming J, Mullen RM, Anam F, Otieno T, Guyatt GH, Taylor GP, Beltrán-Arroyave C, Okwen PM, Nduati R, Kinuthia J, Luma HN, Kirpalani H, Merglen A, Lesi OA, Vandvik PO, Agoritsas T, Bewley S. Antiretroviral therapy in pregnant women living with HIV: a clinical practice guideline. BMJ. 2017

2. Brasil. Ministério da Saúde. Secretaria de Vigilância em Saúde. Departamento de DST, Aids e Hepatites virais. O manejo do HIV na atenção básica - Manuais para profissionais médicos - Brasília: DF, 2015

3. Brasil. Ministério da Saúde. Secretaria de Vigilância em Saúde. Departamento de DST, Aids e Hepatites virais. Indicadores e dados básicos da AIDS nos municípios brasileiros. Brasília: DF, 2016. Available from: http://indicadores.aids.gov.br/ Accessed on 18 november 2017.

4. Brasil. Ministério da Saúde. Secretaria de Vigilância em Saúde. Departamento de DST, Aids e Hepatites Virais. Protocolo de assistência farmacêutica em DST/HIV/Aids: recomendações do Grupo de Trabalho de Assistência Farmacêutica Ministério da Saúde. Brasília: Ministério da Saúde, 2010.

5. United Nations. Sustainable Development Goals. 17 Goals to transform our world. [Internet]. New York: United Nations, New York 2015. Available from: http://www.un.org/ga/search/view_doc.asp?symbol=A/69/L.85\&ampLang=E Accessed on 18 november 2017.

6. Brasil. Ministério da Saúde. Secretaria de Vigilância em Saúde. Programa Nacional de DST e Aids. Protocolo para a prevenção de transmissão vertical de HIV e sífilis: manual de bolso. Brasília: Ministério da Saúde, 2007.

7. Melnyk BM, Fineout-Overholt E. Making the case for evidence-based practice. In: Melnyk BM, Fineout-Overholt E. Evidencebased practice in nursing \& healthcare: a guide to Best practice. Philadelphia: Lippincot Williams \& Wilkins; 2005 [Internet]. 2006 [cited 2015 Oct 7];3-24. Available from: $\quad$ http://download.lww.com/wolterskluwer_vit alstream_com/PermaLink/NCNJ/A/NCNJ_546_156_2010_08_23_SADFJO_165_SDC216.pdf

8. Amaral JS; Silva JC; Carvalho LS; Carvalho NS; Urbanetz AA; Tristão EG. Perda de seguimento e transmissão vertical do HIV na cidade de Joinville, SC - Brasil. Arq. Catarin Med. 2010; 19(1): $1-5$.

9. Silva MJM; Mendez WS; Gama MEA; Chein MBC; Veras DS. Perfil clínico-laboratorial de crianças vivendo com HIV/AIDS por transmissão vertical em uma cidade do Nordeste brasileiro. Rev. Soc. Bras. Med. Trop. 2010; 43(1): 32-35.

10. Quian JR; Gutiérrez SR; González VC; Visconti AG; Sicco GC; Murialdo CE; Lioni MH. Prevención de la transmisión materno-infantil del virus de inmunodeficiencia humana de tipo 1 en Uruguay: 1987-2009. Análisis de las diferentes medidas adoptadas. Rev Chil Infect 2012; 29(1):8794. 
11. Lemos LMD, Rocha TFS, Conceição MV, Silva EL, Santos AHS, Gurgel RQ. Evaluation of preventive measures for mother-to-child Transmission of HIV in Aracaju, State of Sergipe, Brazil. Rev. Soc. Bras. Med. Trop. 2012; 46(6):682-686.

12. Gomes DM; Oliveira MIC; Fonseca SC. Avaliação da testagem anti-HIV no pré-natal e na assistência ao parto no Rio de Janeiro, Brasil. Rev. Bras. Saúde Matern. Infant. 2015; 15(4):413-23.

13. Villarroel J; Álvarez AM; Salvador F; Chávez A; Wu E; Contardo V. Mujeres jóvenes con infección por VIH adquirida por transmisión vertical. Expectativas de tener hijos no infectados. Rev. chil. infectol. 2016; 33(6): 650-655.

14. Brasil. Ministério da Saúde. Secretaria de Atenção à Saúde. Departamento de Atenção Básica. Atenção ao pré-natal de baixo. Brasília: Ministério da Saúde, 2012.

15. Brasil. Ministério da Saúde. Protocolo clínico e diretrizes terapêuticas para prevenção da transmissão vertical de HIV, Sífilis e Hepatites virais. Brasília: Ministério da Saúde, 2017.

16. Melo MC; Ferraz RO; Nascimento JL; Donalisio MR. Incidência e mortalidade por AIDS em crianças e adolescentes: desafios na região sul do Brasil. Ciênc. saúde coletiva. 2016; 21(12): 38893998.

17. Dias MAB. Humanização do parto: política pública, comportamento organizacional e ethos profissional. Rio de Janeiro: Fiocruz, 2010. 189 p.

18. Cartaxo CMB; Nascimento CAD; Diniz CMM; Brasil DRPA. Gestantes portadoras de HIV/AIDS: Aspectos psicológicos sobre a prevenção da transmissão vertical. Estudos de Psicologia. 2013; 18(3): 419-427.

19. Barral MFM; Oliveira GR; Lobato RC; Mendonza-sassi RA; Martínes AMB; Gonçalves CV. Risk factors of HIV-1 vertical transmission (VT) and the influence of antirretroviral therapy (ART) in pregnancy outcome. Rev. Inst. Med. trop. S. Paulo. 2014; 56(2): 133.

20. Lima CTD; Oliveira DR; Rocha EG; Pereira MLD. Manejo clínico da gestante com HIV positivo nas maternidades de referência da região do Cariri. Esc. Anna Nery, 2010;.14(3): 468-476. 